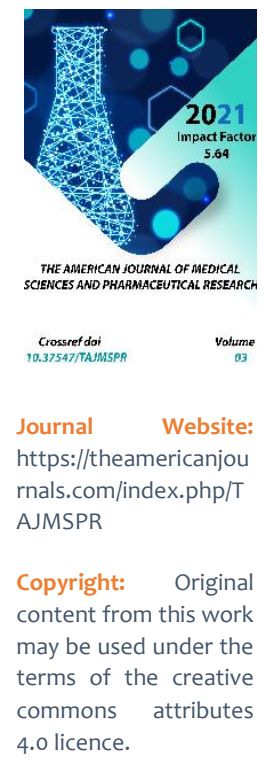

\title{
Improvement Of Treatment Of Odontogenic Cysts Of The Jawbone In Children
}

Bobonazarov Navruz Khabibillaevich

Assistant Of The Department Of Children's Facial-Jaw Surgery, Tashkent State Institute Of Dentistry, Uzbekistan

\section{ABSTRACT}

The improvement of methods of treatment of odontogenic cysts of the jaw remains the actual problem of surgical stomatology. This is caused by the widespread of the disease, the possibility of such complications as cyst abscesses, osteomyelitis development, jaw deformities, tooth loss, pathological fracture occurrence and even the so-called central jaw cancer from the epithelium of cyst walls, and also rather frequent relapses after surgical treatment carried out.

\section{KEYWORDS}

Odontogenic Cysts, Recurrences, Surgical Treatment.

\section{OBJECTIVE OF THE STUDY}

Improvement of treatment of odontogenic cysts of the maxillary bone in children.

\section{INTRODUCTION}

Treatment of Odontogenic cysts remains an urgent problem in surgical dentistry. A widespread of this disease, the development of osteomyelitis as a result of purulent inflammation of the cyst, deformation of the jaw, loss of teeth, jawpatological fracture, even the development of dangerous tumours of the jaw from the epithelium of the cyst wall, and relapse (recurrence) after surgical procedures can be delayed complications. In recent years, in order to increase the effectiveness of postsurgical rehabilitation of the cysts of the 
jawbone and fill the cavity of bone defect, in clinical practice, a variety of biological and medical materials have been developed and their application in the field of surgical intervention has been proposed, which have an active impact on reparative osteogenesis[1,2,4]. Today, Auto - and alloxenotransplants are used, which are prepared in a variety of ways, with the aim of increasing bone regeneration in the area where the surgical procedure is performed. To fill the bone cavities, it is common to use synthetic polymeric materials parallel to this area. Naturally, all of them have contraindications and contraindications for use, depending on the specific situation[18]. The use of blood plasma for filling small bone cavities (no more than $2 \mathrm{~cm}$ ) is sufficient, and the use of this tactic in large cysts is considered ineffective. If the cavity is large in size and it occupies a large arealasa, when the cavity is filled with synthetic and biological materials (ostim-100, gidroxiappatite, gidroxiapol, collapol, brefost, alloxenomaterials, etc.), more active restoration of defects in bone structures occurs[5,7].

Currently, it is proposed to use materials that allow the management and management of regeneration processes in the creation of favorable conditions for the purpose of osteogenetic restoration of bone defects[8]. These materials in the form of absorbable and non-absorbable membranes contribute only to the development and formation of osteogenic structures in the area of bone defect.

In recent years, a new class of materials has been created, which has not only a new bioinerticity, but also a super-elasticity and shape memory effect with new qualities. Due to biochemical, biophysical, biomechanical parameters and biological compatibility of this material with body tissues due to special properties: it has a pronounced softening effect, they have high integrative properties and are devoid of the above disadvantages[10]. Despite the solutions implemented in clinical practice, which are aimed at improving bone reparative processes in the area of bone defects by replacing the cavities formed due to the treatment of the above-mentioned jaws with the help of surgical procedures and the size of the cystous cavities, the presence of sufficient deficiencies in the treatment of the cavities of the jaws with artificial, taking into account the fact that the development of purulent inflammatory processes in the spheres of their import and the cost of recognition raises various problems for practitioners, we have chosen the purpose of our scientific work [12]. Despite the introduction into practice, the preservation of defects in the jawboneogen cyst as a result of which aesthetic and cosmetic insufficiency, anatomical and functional impairment, the continuation of treatment in several stages leads not only to the nervous state of the patient, but also to the loss of children's health for a long period of time. The problem of modern face-jaw surgery - the study of parameters of the lower jaw with the help of 3D X-rays, computed tomography, orthopontomogram, the determination of the area and size of the defect in the lower jaw, the treatment methods supporting the drug "AOSS" in the area of bone defect have been improved[18]. On a global scale, a wide range of scientific and practical studies are being carried out in order to improve the prevention, diagnosis and treatment of the formation of defects after Jaws odontist cysts in medicine. Taking into account the results of densitometric and CT scans, we can list activities aimed at diagnosing, planning 
treatment and improving the quality of life. In our country, measures are being taken to adapt the provision of medical services among the population to the requirements of world standards, including improving the diagnosis and treatment of lower jaw aesthetic and cosmetic defects taking into account the interdependence of anatomical functional disorders[15,16].

\section{RESEARCH MATERIALS AND METHODS.}

In the experimental clinical part of the research, the regenerative properties and application of the drug "A-Oss" developed by the South Korean company were studied. In order to study the reparative effect of osteoplastic material" A-Oss", 97 children diagnosed with Odontogenic cysts of the jaw bones were examined and treated witheksex. Patients were divided into three groups according to the size of the defect in the jaw area. In the first group, depending on the location of the pathological process, it was allocated to the frontal, premolar and distal areas (Table 1).

Table 1. Group of patients

\begin{tabular}{|c|c|c|}
\hline Pathological sphere & Main group & control group \\
\hline Frontal & 25 & 15 \\
\hline Premier & 28 & 13 \\
\hline Distal & 15 & 10 \\
\hline Overall & 68 & 31 \\
\hline
\end{tabular}

X-ray examination was characterized by a clear boundary absorption in the bone tissue in the form of a circle, and it was seen that the causative tooth root tip was adjacent to the Cystic cavity. , From 2019 to 2021, 117 patients were examined and treated with odontal ovarian cysts of the jawbone in the children's facial-jaw Department of the Tashkent State Institute of Dentistry. Clinical studies were conducted in a 9-15-year-old patient with a defect formation of 97 jaw cysts, of which 9-11year-olds are 37, 11-13-year-olds are 32, 14-15year-olds are 28, 56 are ugil children and 41 are girls. In order to assess the effectiveness of the use of "A-Oss"in eliminating the defect formed after the jaw operations, the main and control groups were formed. In the patients in the main group, 68 of them during the operation, the bone defect area was supplemented with A-Oss. Patients who underwent exactly such an operation were included in the control group and, unlike the main group, "A-Oss"was not used.

The number of patients in the group was 3 people. The indicators of age and sex of the examined patients were expressed in 1,2 diagrams. 
The American Journal of Medical Sciences and Pharmaceutical Research

(ISSN - 2689-1026)

Published: September 29, 2021 | Pages: 50-60

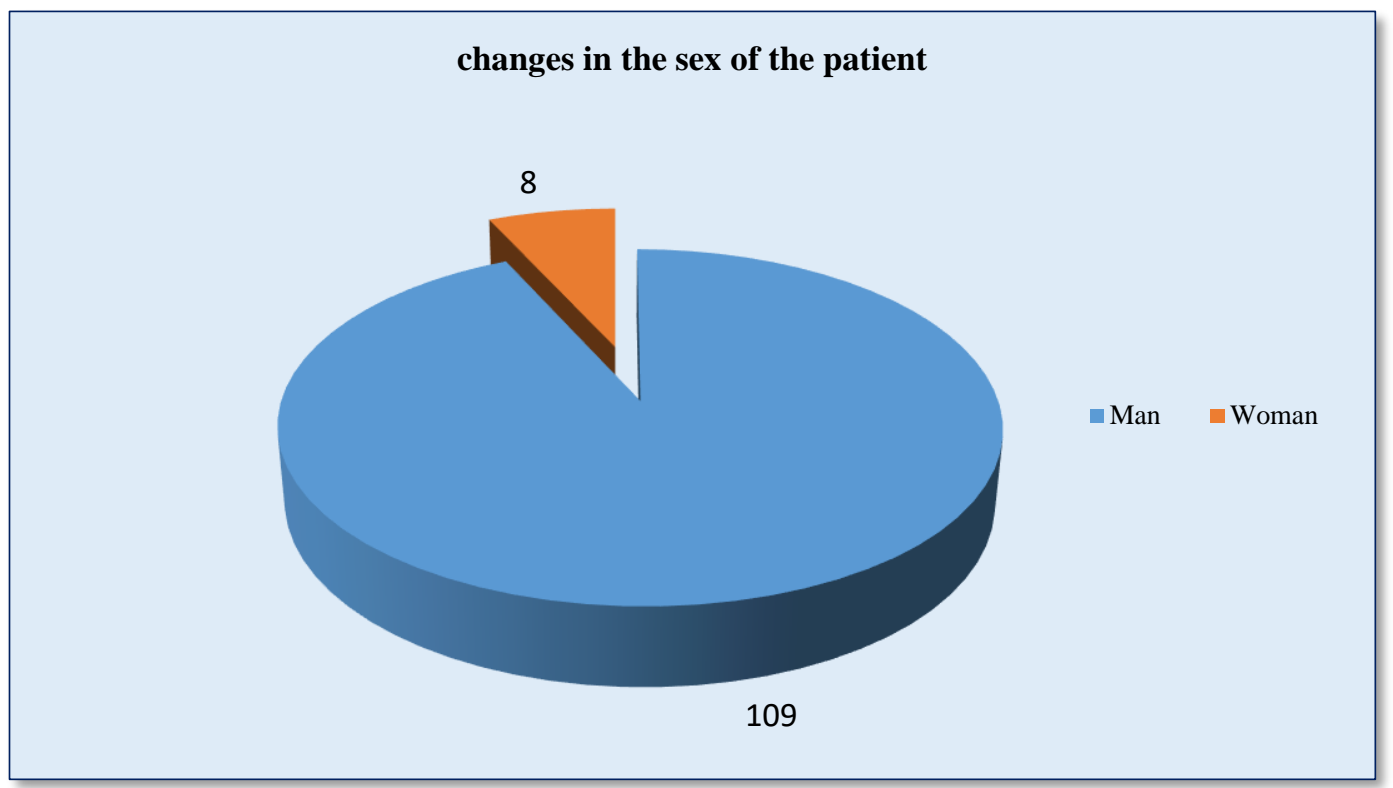

Diagram №1.

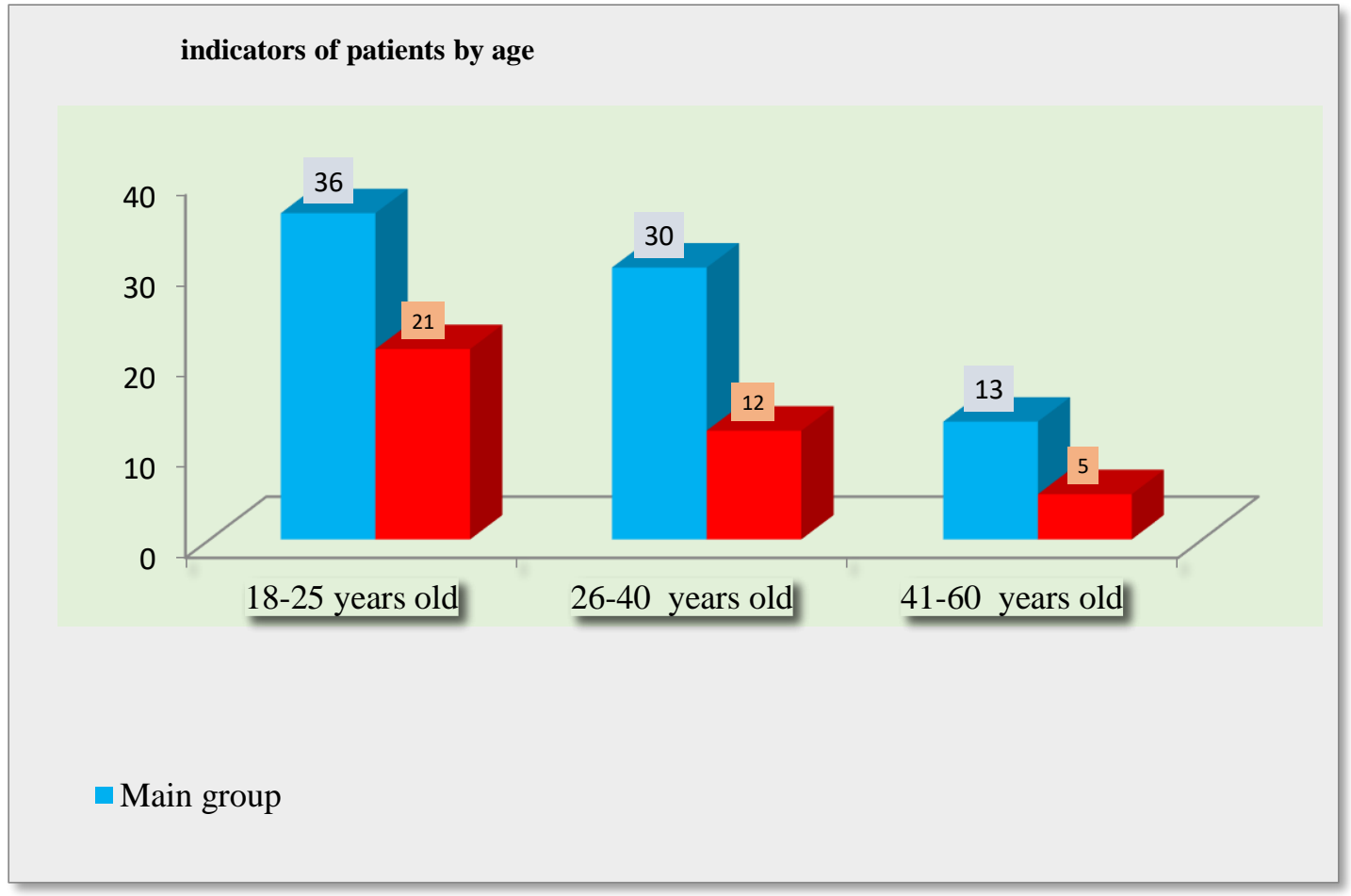

Diagram №2 


\section{Evaluation of clinical examination results.}

The effectiveness of the treatment was determined by assessing the post-operative period courses, as well as the results of the instrumental examination in the main and control group. Evaluation of the results of treatment was carried out within a year from the date of the operation. The rate and quality of bone tissue recovery, the rate of absorption of the material used, patient complaints and repeated visits were analyzed.The analysis of the near and long-term results of surgical treatment of patients was carried out according to the following indicators:

1. Appetite

2. Lack of.

3. Pain in the wound.

4. Body temperature.

5. Edema and hematoma after surgery.

6. Sutures stand.

7. Separation separation from the wound.

8. Wound healing.

\section{Indicators of densitometric examination.}

It was carried out on the basis of the program "Image J", based on the optical nurni absorption of tissue to determine the regeneration processes in the bone defect area of patients. Patients were studied before the operation, 1-day after opression, 1-month, 3month, 6-month and 1-year-long orthopontomographs. When studied through "Image J", it was observed that the optical density of the healthy bone cortical plate is up to 170 , the optical density of the porous bone is around 150. The beginning of bone regeneration in the area where the operation was performed was from $40 \pm 5$ units to $165 \pm 5$ units.

\section{Indicators before the operation.}

Before the operation, we had almost identical indicators of optical nurni conduction performance in patients of both groups. 5 points in the area of the defect: one central and one hour stretch, and the points in the area of 12, 4, 8 were measured. The lowest figure is 25 units the upper figure is 45 units (Tab.2).

Table 2. 1 day after the operation

\begin{tabular}{|c|c|c|c|c|c|c|}
\hline & \multicolumn{3}{|c|}{ Main group $\mathrm{n}=79$} & \multicolumn{3}{c|}{ Control group $\mathrm{n}=38$} \\
\cline { 2 - 7 } & $\begin{array}{c}\text { Average } \\
\text { indicator }\end{array}$ & $\begin{array}{c}\text { lowest } \\
\text { indicator }\end{array}$ & $\begin{array}{c}\text { highest } \\
\text { indicator }\end{array}$ & $\begin{array}{c}\text { Average } \\
\text { indicator }\end{array}$ & $\begin{array}{c}\text { lowest } \\
\text { indicator }\end{array}$ & $\begin{array}{c}\text { highest } \\
\text { indicator }\end{array}$ \\
\hline 1. point & $38 \pm 5$ & 25 & 38 & $39 \pm 5$ & 25 & 39 \\
\hline 2. point & $42 \pm 5$ & 25 & 30 & $42 \pm 5$ & 23 & 31 \\
\hline 3. point & $42 \pm 6$ & 30 & 48 & $38 \pm 6$ & 32 & 45 \\
\hline 4. point & $39 \pm 5$ & 26 & 40 & $42 \pm 5$ & 26 & 39 \\
\hline $\begin{array}{c}\text { Middle } \\
\text { indicator }\end{array}$ & \multicolumn{3}{|c|}{$40,2 \pm 5$} & \multicolumn{3}{|c}{$40,3 \pm 5$} \\
\hline
\end{tabular}


The application of postoperative osteoplastic material in patients-the lowest when measuring four points in the blood 25 the highest index was 40 the total average index 40. In contrast to the control group, when four points were measured in the field of Osteon TM II Collagen, which was used in the field of defects in the main group of patients, the lowest index was 40, the highest index was 55 (Tab.3).

Table 3. Indications for the use of postoperative osteoplastic material in patients

\begin{tabular}{|c|c|c|c|c|c|c|}
\hline & \multicolumn{3}{|c|}{ Main group $\mathrm{n}=79$} & \multicolumn{3}{c|}{ Control group $\mathrm{n}=38$} \\
\cline { 2 - 7 } & $\begin{array}{c}\text { Average } \\
\text { indicator }\end{array}$ & $\begin{array}{c}\text { lowest } \\
\text { indicator }\end{array}$ & $\begin{array}{c}\text { highest } \\
\text { indicator }\end{array}$ & $\begin{array}{c}\text { Average } \\
\text { indicator }\end{array}$ & $\begin{array}{c}\text { lowest } \\
\text { indicator }\end{array}$ & $\begin{array}{c}\text { highest } \\
\text { indicator }\end{array}$ \\
\hline 1 point & $48 \pm 5$ & 40 & 49 & $38 \pm 5$ & 25 & 39 \\
\hline 2 point & $50 \pm 5$ & 42 & 50 & $43 \pm 5$ & 26 & 31 \\
\hline 3 point & $49 \pm 6$ & 43 & 51 & $39 \pm 6$ & 28 & 42 \\
\hline 4 point & $52 \pm 5$ & 41 & 51 & $41 \pm 5$ & 26 & 39 \\
\hline $\begin{array}{c}\text { Middle } \\
\text { indicator }\end{array}$ & \multicolumn{3}{|c|}{$40 \pm 5$} & \\
\hline
\end{tabular}

Results of the examination no later than a month after the operation. The application of postoperative osteoplastic material in patients-the lowest index was 35 the highest index 50 when four points were measured in the blood, the total average was $45 \pm 5$. In contrast to the control group, when four points were measured in the field of Osteon TM II Collagen, which was used in the field of defects in the main group of patients, the lowest index was 65, the highest index was 80 , the average total index was 76 units.

Table 4. Indications for the use of postoperative osteoplastic material in patients

\begin{tabular}{|c|c|c|c|c|c|c|}
\hline \multirow{2}{*}{} & \multicolumn{3}{|c|}{ Main group $\mathrm{n}=79$} & \multicolumn{3}{c|}{ Control group $\mathrm{n}=38$} \\
\cline { 2 - 7 } & $\begin{array}{c}\text { Average } \\
\text { indicator }\end{array}$ & $\begin{array}{c}\text { lowest } \\
\text { indicator }\end{array}$ & $\begin{array}{c}\text { highest } \\
\text { indicator }\end{array}$ & $\begin{array}{c}\text { Average } \\
\text { indicator }\end{array}$ & $\begin{array}{c}\text { lowest } \\
\text { indicator }\end{array}$ & $\begin{array}{c}\text { highest } \\
\text { indicator }\end{array}$ \\
\hline 1 point & $68 \pm 5$ & 65 & 69 & $46 \pm 5$ & 35 & 45 \\
\hline 2 point & $73 \pm 5$ & 69 & 76 & $43 \pm 5$ & 41 & 50 \\
\hline 3 point & $70 \pm 6$ & 66 & 67 & $41 \pm 6$ & 40 & 54 \\
\hline 4 point & $69 \pm 5$ & 67 & 71 & $45 \pm 5$ & 38 & 49 \\
\hline $\begin{array}{c}\text { Middle } \\
\text { indicator }\end{array}$ & \multicolumn{3}{|c|}{$45 \pm 5$} \\
\hline
\end{tabular}




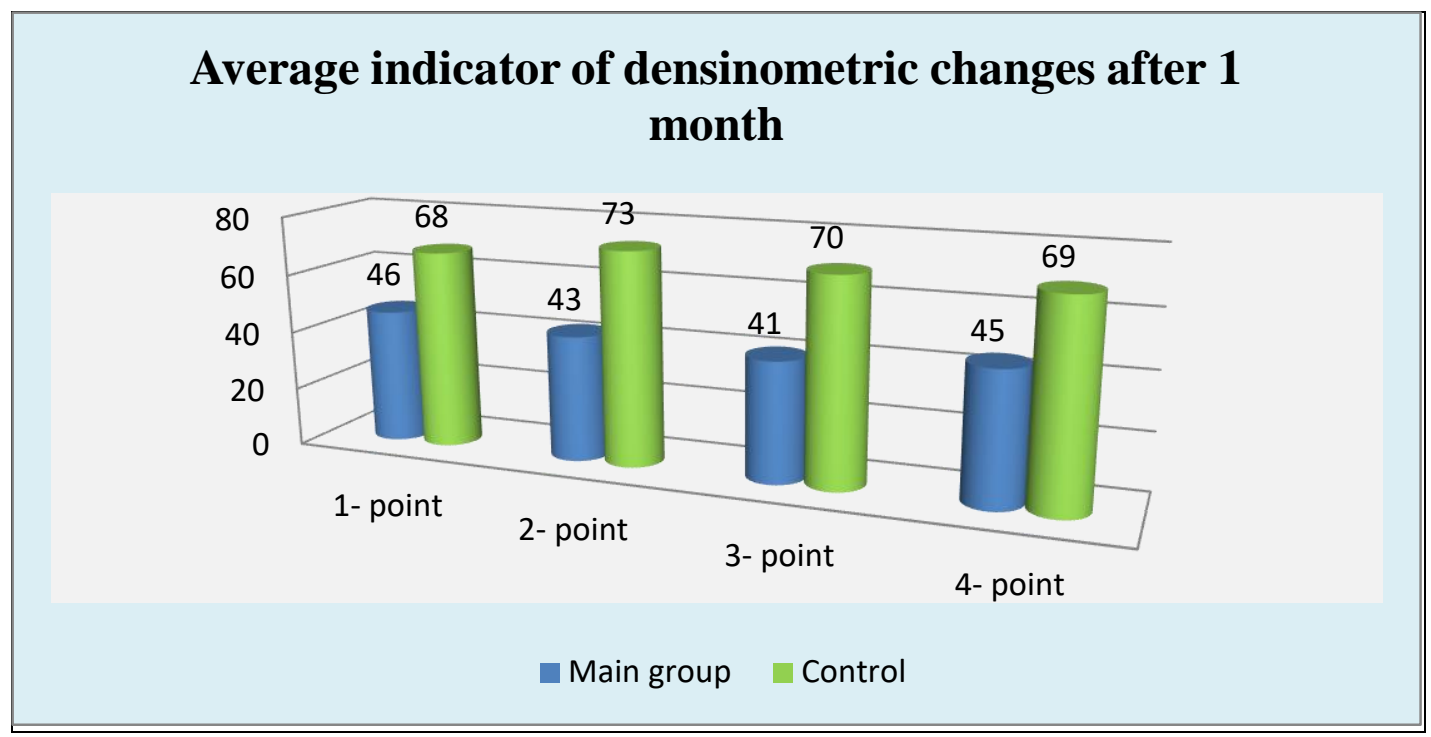

Diagram №2.

The results of the examination no later than three months after the operation. Three months later, investigations showed visible results that the osteoplastic material placed in the area of bone defect is accelerating the regeneration process. In the main group of patients after the operation, when the optical density of the points highlighted above in the area of the defect was determined, the lowest indicator was 75, the highest indicator 97, and the average overall indicator was 90 units. When the osteoplastic material was not used, it was differentiated with the following results in accordance with the above indicators: 45 , 60, 55 (Tab. 5).

Table 5. Deficiency rate in the main group of postoperative patients

\begin{tabular}{|c|c|c|c|c|c|c|}
\hline & \multicolumn{4}{|c|}{ Main group $\mathrm{n}=79$} & \multicolumn{3}{c|}{ Control group $\mathrm{n}=38$} \\
\cline { 2 - 7 } & $\begin{array}{c}\text { Average } \\
\text { indicator }\end{array}$ & $\begin{array}{c}\text { lowest } \\
\text { indicator }\end{array}$ & $\begin{array}{c}\text { highest } \\
\text { indicator }\end{array}$ & $\begin{array}{c}\text { Average } \\
\text { indicator }\end{array}$ & $\begin{array}{c}\text { lowest } \\
\text { indicator }\end{array}$ & $\begin{array}{c}\text { highest } \\
\text { indicator }\end{array}$ \\
\hline 1 point & $89 \pm 5$ & 75 & 90 & $56 \pm 5$ & 45 & 59 \\
\hline 2 point & $91 \pm 5$ & 69 & 97 & $53 \pm 5$ & 41 & 60 \\
\hline 3 point & $91 \pm 6$ & 66 & 89 & $56 \pm 6$ & 40 & 54 \\
\hline 4 point & $89 \pm 5$ & 67 & 89 & $55 \pm 5$ & 48 & 59 \\
\hline $\begin{array}{c}\text { Average } \\
\text { densito } \\
\text { metric } \\
\text { index }\end{array}$ & $90 \pm 5$ & & & & $55 \pm 5$ & \\
\hline
\end{tabular}

Clinical sample №1 patient T.M. year of birth 2008. History of the disease № 3566/351. The patient brought his mother to complain of a strong pain in the jaw, complete closure of the mouth, pain when the teeth touched each other, bleeding in the mouth, general malaise, 
headaches. The patient did not associate this process with anything xech. In radiography, a radical cyst of the upper jaw is detected. Local position: 5,6,7 area of the upper jaw alveolar tumor on the surface of the vestubular atrophy of the upper jaw with a clear Border round shape visual clinical course of edema, without changes in the color of the mucous membrane, painless when palpated, the sign of" scraping of parchment paper" is determined. In radiography, a radical cyst of the upper jaw is detected.

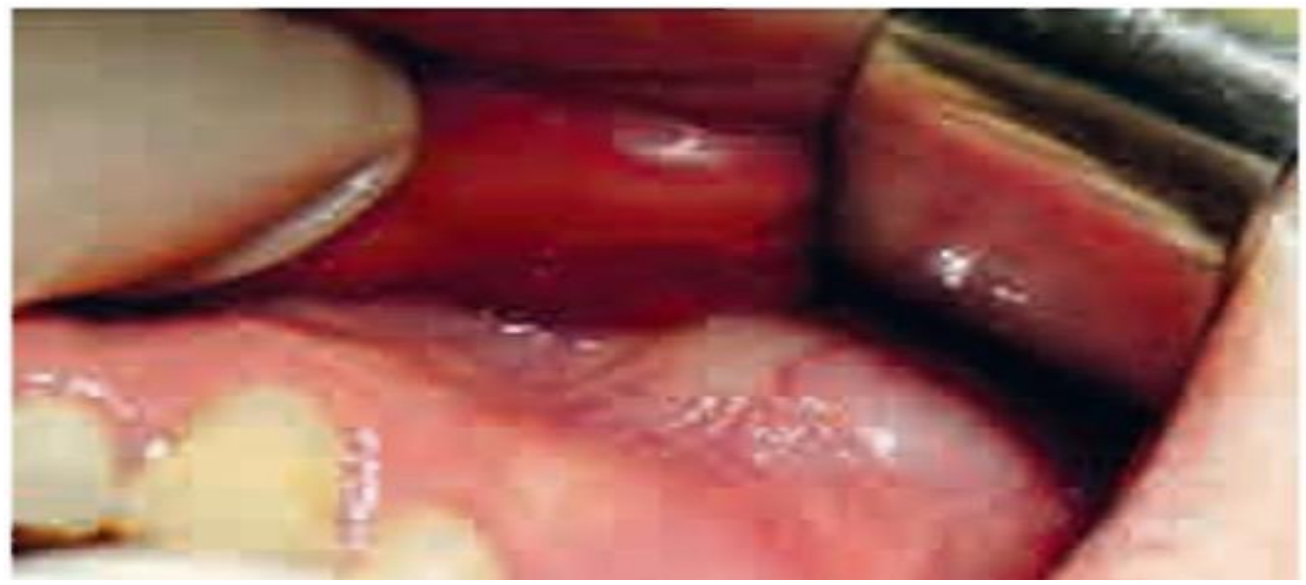

Figure 1. Clinical picture of the cyst.

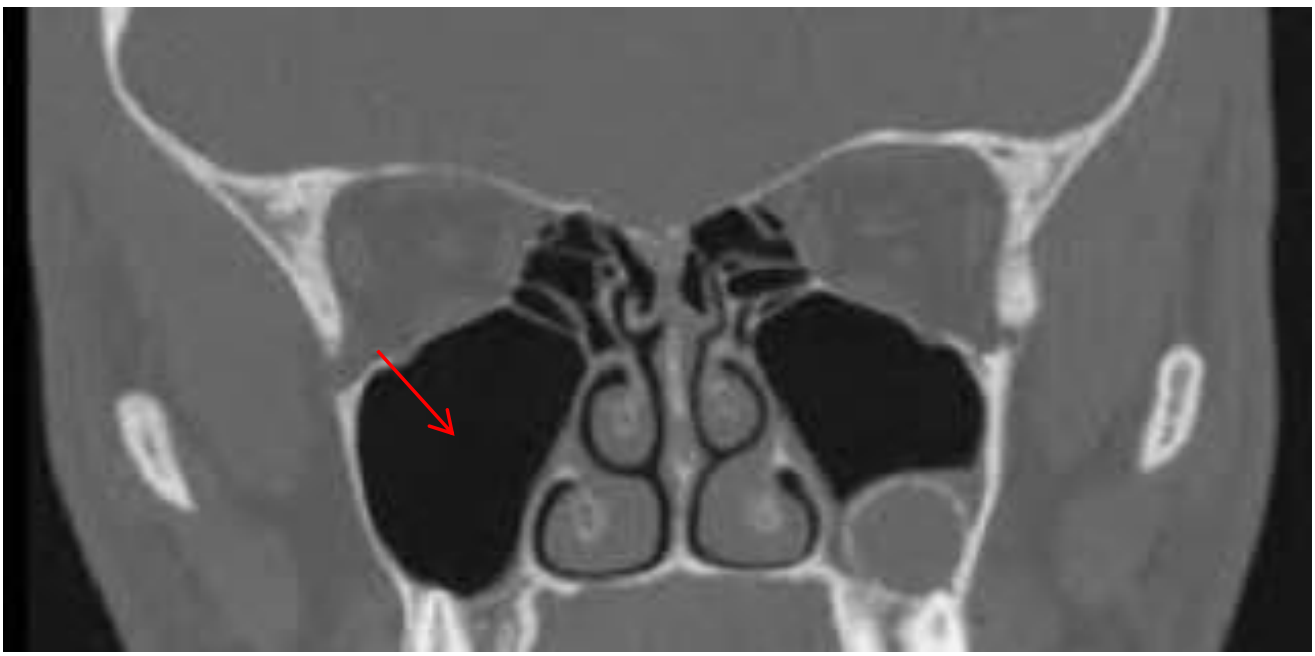

Figure 2. K T.Diagnosis: cyst in the area of the upper jaw 


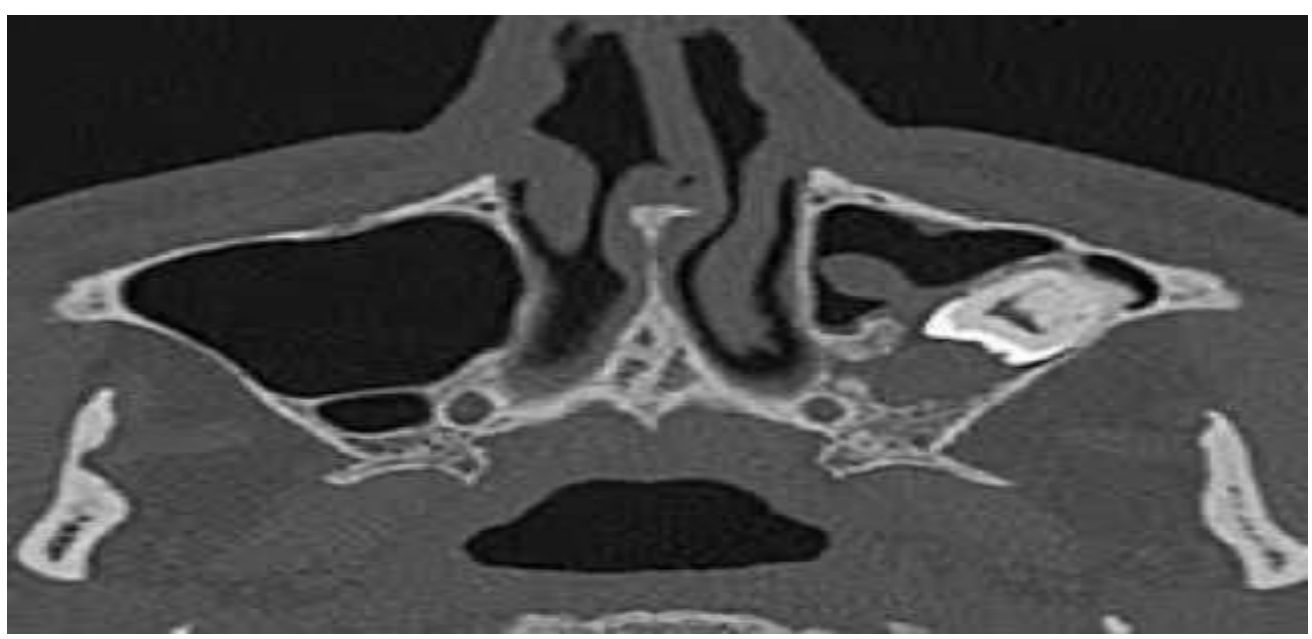

Figure 3. Instead of removing the cyst and its pleura was put osteoplastic material "A-Oss

\section{CONCLUSION}

1. By day 7 , under the influence of a-Oss closure with osteoplastic material, the defect in the bone formed by the experiment came to fill the entire area of the bone defect, entering the elastic form into the collagen formation in the composition, softening and porosity as a result of the growth of blood vessels in day 14, 21- on the day bone tissue interacts around the blood vessels between the blood vessels, in 30 days, the development of concentric bone plates from the bone tissue around the blood vessels, which grows in bone material, in 60 days, the formation of concentric bone plates between the bone material is completed by turning into plasticized bone tissue.

2. Advantages of the osteoplastic material (in the example of" a-Oss") when bone material is applied, the adhesion of osteoblasts to the bone surface and the formation of a bone layer consisting of collagen fibers, the collagen layer is absorbed, the penetration of blood vessels between the substance intensively, osteoblasts accelerate the process of bone formation, initially coarse fiber, then plasticized bone is formed.

\section{REFERENCES}

1. Rudneva A. (2010). Experimental study of biocompatibility of tissueengineered matrix based on a new veterinary drug "TIOPROST-M". Siberian Bulletin of Agricultural Science, (3). 76-81.

2. Gintsburg., A.L. (2011). Development of new generation drugs for effective regeneration of bone tissue . Treatment and prophylaxis. (1). pp.8084.

3. Pankratov A.S., Lekishvili M.V. (2011). Bone plasty in dentistry and maxillofacial surgery. Guidelines for doctors. Moscow. pp.15-32,

4. Sakharov A. V., Glotova A. A., Makeev A. A. Comparative study of bone tissue reparative regeneration using tissue- 
engineered matrix on the basis of TIOPROST material and Collapan-M material. Cell Transplantology and Tissue Engineering. 20 П. 6(4). pp.8994.

5. Sashkina T.N., Bondarenko M.A., Druzhinina R.A., Dubrovin D.S. (2003). Experimental evaluation of the effectiveness of Polioxidonium in immunodeficiency by indicators of the cell composition of peripheral blood. In the book: Man and medicine, P 659.

6. V. Sirak, A.Ch. Tskhovrebov, L.Y. Plakhtii (2011). Experimental substantiation of application of osteoplastic material "Collost" for replacement of bone tissue defects. Dentist. (7). 34-39.

7. Sletov A.A. (2012). Replacement of jawbone defects with osteoplastic materials. Ph. D. in medical sciences, Moscow

8. I.S. Alekseeva (2012). Comparative assessment of bone tissue formation efficiency in transplantation of tissueengineered construct and osteoplastic material "bio-oss" in the maxillary sinus floor area. Dentistry. 91(6). 41-44.

9. Tankaev A.S. (2002). Application of domestic osteoplastic materials to increase the effectiveness of immediate dental implantation. Abstract of thesis of Candidate of Medical Sciences. D. in medical sciences, Moscow,. $23 \mathrm{C}$.

10. L.T. Volova. (2013). Testing of osteoplastic materials used in dentistry on cells of mesenchymal origin. Morphological Bulletin. (3). 21-27.

11. A.A. Muraev. (2012). Toxicity and biological activity of a new bone substituting material based on non- demineralized collagen containing vascular endothelial growth factor. Modern technologies in medicine.( 3). 19-25.

12. Grant, A. M., Avenell, A., \& Campbell, M. K. (2005). Randomised placebocontrolled trial of daily oral vitamin $\mathrm{D}_{3}$ and/or calcium for the secondary prevention of low trauma fractures in the elderly. Lancet, 365, 1621-1628.

13. Tsiridis, E., Ali, Z., Bhalla, A., Heliotis, M., Gurav, N., Deb, S., \& DiSilvio, L. (2007). In vitro and in vivo optimization of impaction allografting by demineralization and addition of rh-OP1. Journal of Orthopaedic Research, 25(11), 1425-1437.

14. Kadyrovich, K. N., Erkinovich, S. K., \& Ilhomovna, K. M. (2021). Microscopic Examination Of Postcapillary Cerebral Venues In Hemorrhagic Stroke. The American Journal of Medical Sciences and Pharmaceutical Research, 3(08), 69-73.

15. Shomurodov K.E. (2010). Peculiarities of cytokine balance in gingival fluid at odontogenicphlegmon of maxillofacial area. The doctor-aspirant. 42(5.1). - C. 187-192.

16. Isomov M.M., Shomurodov K.E. (2020). Peculiarities of rehabilitation of pregnant women with inflammatory diseases of maxillofacial area. International scientific-practical conference "Modern aspects of complex dental rehabilitation of patients with maxillofacial defects" May 21-22, 2020, Krasnodar. C. 72-76.

17. Scafati, C. T. (2005). Anchor screw, a valuable technique in facial fractures and cranio-maxillofacial surgery. 
The American Journal of Medical Sciences and Pharmaceutical Research

(ISSN - 2689-1026)

Published: September 29, 2021 | Pages: 50-60

IMPACT FACTOR

2021: 5.64

Doi: https://doi.org/10.37547/TAJMSPR/Volume03Issue09-10

OCLC - 1121105510

Journal of Cranio-Maxillofacial Surgery, 33(5), 331-333.

18. Zuk, P. A., Zhu, M., Ashjian, P., De Ugarte, D. A., Huang, J. I., Mizuno, H., ... \& Hedrick, M. H. (2002). Human adipose tissue is a source of multipotent stem cells. Molecular biology of the cell, 13(12), 4279-4295. 